\title{
Women's Low Participation in Top Leadership Positions in North Shoa Zonal Administration, Amhara Region, Ethiopia: Its Determinants
}

\author{
Abebe Getaneh Kebede* \\ Lecturer, Department of Management, College of Business and Economics, Debre Berhan University, Ethiopia \\ Co-Author: Negesse Bogale Tefera \\ Lecturer, Department of Management, College of Business and Economics, Debre Berhan University, Ethiopia
}

\begin{abstract}
Women represent over half of the Ethiopian population, but their participation in different leadership positions of public institutions is vastly underrepresented. Women in North Shoa zone administration also experiencing this problem. Therefore, in order to investigate the determinants of this problem, demographic factors such as age and marital status; personal factors, organizational factors and socio-cultural factors were considered in the study. Both descriptive design and explanatory design were employed. $95.49 \%$ response rate was used in the study. Simple random sampling and judgmental sampling technique were used to select sample respondents. Data were collected from primary sources through structured questionnaires. Pearson correlation, cross tabulation and multiple linear regressions were employed. $\operatorname{Age}(\beta=0.08, \mathrm{P}<.001)$, marital status $(\beta=0.346, \mathrm{p}<0.01)$, personalfactors $((\beta=0.320, p<0.01)$,organizational factors $(\beta=0.290, P<0.001)$ and socio-cultural factors $(\beta=0.213, p<0.01)$ had significant effect on women's participation in leadership positions in the study area. Accordingly, recommendations were forwarded so as to increase the participation of women's in leadership positions in the study area.
\end{abstract}

Key Terms: Determinants, women, leadership positions, North Shoa Zonal Administration

DOI: $10.7176 / \mathrm{DCS} / 11-8-03$

Publication date:October $31^{\text {st }} 2021$

\section{Introduction}

The low participation of women in any aspect of life has become an issue in all over the world and they are frequently excluded from position of power. This situation has affected women in many ways and results violation of their rights (ThorntonB., 2012). Women in Africa have been faced with similar challenges and obstacles to their wellbeing and development including exclusion among others in leadership positions (Genet and Habtu, 2011).This fact is also true in Ethiopia. Women represent over half of the Ethiopian population, but their participation in different managerial positions of public institutions is vastly underrepresented (Wubante D., 2018).

The nationwide policy on women which is formulated in 1993 aimed to address gender in equality in the social, economic and political aspects and to create strategies \& policies on gender issues of the country particularly on women`s empowerment. However, the practice implies low participation of women especially in leadership positions (Genet B., 2020). However, without gender equality and women's empowerment policy measures, it is hardly possible for least developed countries like Ethiopia to realize poverty reduction goals, millennium development targets and sustainable development objectives (Ogato, 2013). Lack of academic qualification, gender stereotyping, over burden of domestic responsibility, lack of confidence, lack of support at home and work place, religious practice, lack of experience are the main factors that hindered women's empowerment in leadership position in Ethiopia (Nigist M., 2019). Triple role, violence against women, lack of education and so on, their representation and participation in leadership and decision making position has also been limited women from participation in leadership in Ethiopia(Gojjam A. and Minijit S.2015). Many studies were done on this area in different institutions previously. For example, Gojjam A. and Minijit S.(2015) conducted a research on factors affecting women's participation in leadership and management in selected public higher education institutions in Amhara Region, Ethiopia and stereotyping, patriarchy, lack of support system at work, low academic qualification and lack of role model were found as the major barriers stifling women to assume leadership positions.

According to the data obtained from North Shoa Zone Civil Service Memriya (2021) report, currently there are 33 top leadership positions in North Shoa Zonal administrations. Only 9 (27.27\%) of the positions are occupied by women while $40.55 \%$ of employees in the administration are women. These facts indicate the low participation of women in top leadership positions in Zonal Administration of North Shoa. However, as far as the researcher concerned, there is no published study in this area. Furthermore, the findings from the previous studies on similar problem done by Gojjam A and Minijit S.(2015),Wubante D.(2018) and Genet B.(2020) have been inconsistent, giving practitioners no clear answers to what actions would be beneficial to follow. Thus, in this regard an attempt 
to support the generalizability of the area is needed. Thus, this study intends to investigate determinants of women's participation in top leadership positions in North Shoa Zonal Administration, Amhara region, Ethiopia. The next section of the paper is organized as follows: the next section provides literature review on the factors influencing women's participation in top leadership positions and related issue which supports the study followed the methodology section used in the study. The findings and discussion are presented in 'results and discussion section and the final sections offer some conclusion and recommendations.

\section{Literature Review}

\section{Determinants of Women's Participation in Leadership Positions}

Personal Factors

The underrepresentation of women in leadership position of any kind affects women negatively in many aspects: economically, socially and psychologically. This result in poor contribution for development, in equality of women and men, depression and de motivation of women for work, absence of role models for women(Genet B.,2021). Singh and Shahabudin, 2000 cited in Gojjam A. and Manjit S, 2016 also identified personal factors such as, assertiveness, confidence, resourceful creativeness, loyalty and trustworthiness which could help women to ascend to senior management positions. Furthermore, the findings of Getachew (2014) revealed that personal factors such as, informal network of men which favors them to be leaders, lack of interest due to women's self-image is low. Similarly Birhanu(2013)conducted research on Challenges and opportunities of educating women's leadership and action in their mission for emancipation and change and stated that in Ethiopia there is lack of confidence in women's capabilities of leader ship in which it inhibit women's from participating in leadership positions. According to Rahel(2013) found that women manager faced lack of self-confidence and have a tendency not to accept their ideas and suggestions.

\section{Socio-cultural Factors}

Socio cultural factors are perceptions of the society which are constructed gender based role is very serious in obstacle for women from leadership position. The findings of the study of Netsanet (2013), confirms that the negative attitude of organization who hire women take the a lion share of becoming barrier to women participation in leadership. Wubante D.(2018) also studied factors affecting women participation in managerial positions in Debre Berhan Town and the results of the study revealed that patriarchy was the major challenge that affects women's participation in managerial positions of public institutions. A patriarchal corporate culture is the significant factor for women to rise to senior management (Corporate Gender Gap Report, 2010). In most countries, women are perceived to have primary responsibilities as wives and mothers.

\section{Organizational Factors}

According to Woinshet (2015), the major obstacle in women's career development and their advancement to leadership positions is the male-preferring organizational culture. They are still trying to succeed in what is traditionally male dominated organizational culture. Another study was conducted by Genet B.(2021)entitled to "Factors Affecting Women Participation in leadership position in Debre Markos city administration" by using organizational, socio culture and individual factors as explanatory variables and it was found organizational factors such as lack of giving due recognition for women's performance had the major contribution for low participation of women in leader ship position. Lack of mentoring; fewer opportunities for training and development of women; low aspiration level of women managers and gender stereotypes were found barriers to the career advancement of women to top management positions (Okafor et al. 2011) .

\section{Gap of Literatures}

Previous literatures mentioned above, both theoretical and empirical literatures, focus on the factors affecting women's low participation in leadership positions mainly personal factors, organizational factors and sociocultural factors. However, demographic factors such as age, marital status and others have not been considered yet. The influence of being married and single; being youth, adult and old aged is obvious though studies were not done on their extent of influence on women participation in leadership positions. Thus, this study incorporated them in addition to the personal factors, organizational factors and socio-cultural factor.

\section{Research Methodology}

\subsection{Study Area Profile}

The study was conducted in North Shewa which is one of the 11 administrative zones of Amhara National Regional State, Ethiopia. It is located in between $9^{\circ}-11^{\circ} \mathrm{N}$ latitude, and $38^{0}-40^{0} \mathrm{E}$ longitudes with an area of about 15 , $936 \mathrm{~km}^{2}$. According to the Central Statistical Agency of Ethiopia (2007), North Shewa had a total population of 1,837,490; 928,694 men and 908,796 women. 


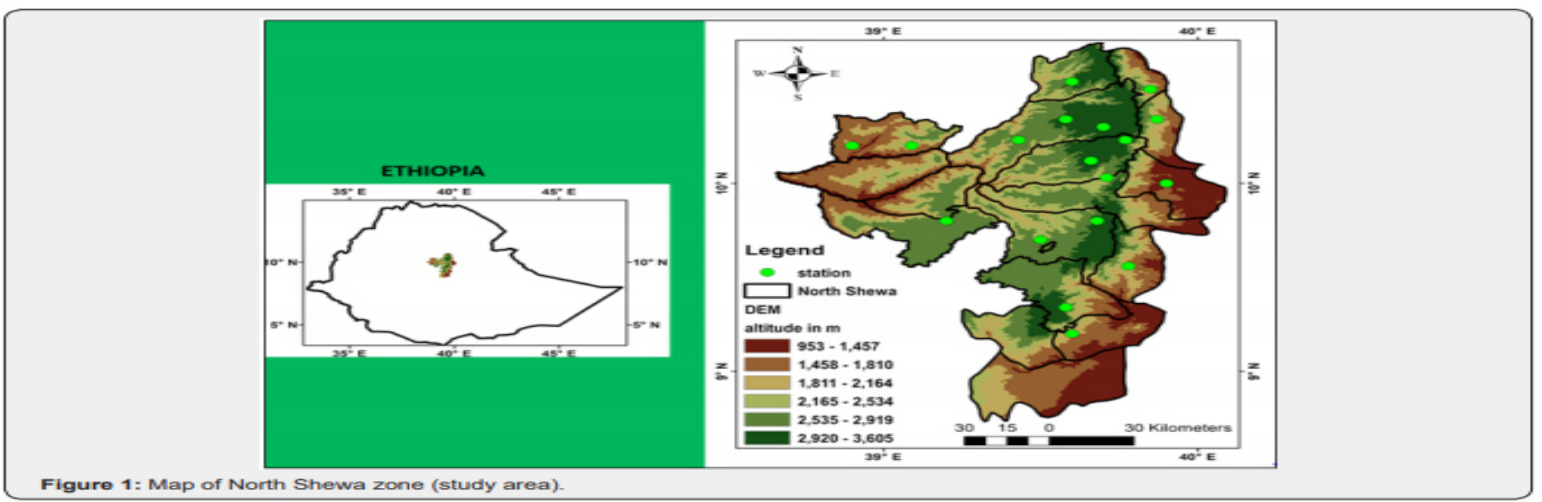

\subsection{Research Design and Approaches}

Both Descriptive research design and explanatory research design. Descriptive research design was used in the study so as to describe the existing phenomenon on women participation in leadership position in the study area where as explanatory design was employed in order to analyse the cause and effect relationship of the independent variables and dependent variable in the study. Regarding the research approach, mixed research approach was employed it was because both structured research and semi structured interview were used in the study.

\subsection{Source and Methods of Data Collection}

Both primary and secondary data were used in the study. Primary data were collected through structured questionnaire adopted from Genet B.(2020).The variables of the study except age and marital status were measured in 5 points Likert scale from 1, strongly disagree to 5 , strongly agree. The questionnaire was prepared in the English language then translated in to local language (Amharic language) to make easy for communication. Besides, the questionnaire was pre-tested. Secondary data were gathered from 2021 report of North Shoa Zone Civil Service Memriya.

\subsection{Sampling Technique and Sample Size Determination}

The study used judgmental and simple random sampling designs in the survey. Judgemental sampling technique was used to select the nine women occupying the top leadership positions in the study area. This study applied a simplified formula provided by Yamane (1967) to determine the required sample size at $95 \%$ confidence level and $5 \%$ the margin of error. Yamane formula is expressed as; $n=N /\left(1+N\left(e^{\wedge} 2\right)\right)=1016 /(1+1016[0.0025])=288$

Where: $\mathrm{n}=$ sample size; $\mathrm{N}=$ the total number of women employees in the study area and $\varepsilon=$ error tolerance or margin of error.

\subsection{The Methodology of Data Analysis}

The collected data from different sources, data were coded and entered in to SPSS software version 23. Then after, data analysis was done by using both descriptive statistics such as mean, frequency and percentage. Mean of the scores of manifests of all independent variables in the study except age and marital status was computed and the mean scores were used in running the linear regression and correlation analysis. Furthermore, inferential statistics such as cross tabulation, Pearson correlation and multiple linear regressions were used to examine the determinants of participation of women in leadership position.

\subsection{Model Specification}

The main aim of this study was to explore the determinants of women participation in top leadership position in the study area. Supposed that, organizational factors, personal factors, socio-cultural factors, age and marital status are uncorrelated with error term, the determinants of participation of women in top leadership position are specified as follow;

Participation of women in top leadership position $=\beta_{0}+\beta_{1}$ (personal factors) $+\beta_{2}$ (organization factors) $+\beta_{3}$ (socio-c $\alpha_{0}$ ultural factors) $+\beta_{4}$ (Age) $+\beta_{5}$ (Marital status) $+\varepsilon$. Where $\beta_{0}$ is the constant; $\beta_{1}, \beta_{2}, \beta_{3}, \beta_{4}$ and $\beta_{5}$ are coefficients of respective predicators and $\varepsilon$ is error term

\section{Results and Discussion}

\subsection{Descriptive Statistics}

This research interprets and analysis the findings gathered from primary and secondary sources. The results of the study focused on the determinants of women's participation in top leadership position. The finding has been 
presented and analysed under the following themes:

Table 4.1. Demographic variables influencing Women's Low Participation in leadership Positions

\begin{tabular}{|c|c|c|c|c|c|c|}
\hline \multicolumn{2}{|c|}{ Demographic Variable } & \multicolumn{3}{|c|}{$\begin{array}{l}\text { I have top or deputy leadership } \\
\text { position }\end{array}$} & \multirow{5}{*}{$\begin{array}{l}\text { Chi-square } \\
\text {. } \\
11.165\end{array}$} & \multirow{2}{*}{$\begin{array}{l}\text { P-value } \\
001 * *\end{array}$} \\
\hline \multirow{4}{*}{ Marital status } & & Yes & No & Total & & \\
\hline & Single & 0 & 150 & 150 & & \\
\hline & Married & 9 & 116 & 225 & & \\
\hline & Total & 9 & 266 & 275 & & \\
\hline \multirow{6}{*}{ Age } & $<25$ & 0 & 23 & 23 & \multirow[t]{6}{*}{20.305} & \multirow[t]{6}{*}{$.000 * *$} \\
\hline & $26-30$ & 0 & 53 & 53 & & \\
\hline & $31-40$ & 8 & 61 & 69 & & \\
\hline & $41-50$ & 1 & 101 & 102 & & \\
\hline & $>50$ & 0 & 28 & 28 & & \\
\hline & Total & 9 & 266 & 275 & & \\
\hline
\end{tabular}

Note: * and ** are level of significance at 5 and $1 \%$ respectively.

As shown in table 4.1 above, among 150 single women employees, none of them occupy neither top nor deputy leadership position; whereas among 225 married women employees nine of them hold either a top or deputy leadership positions. The chi-square test result revealed that marital status had statistically significant association $\left(\mathrm{X}^{2}=11.165, \mathrm{p}<.001\right)$ with women participation in leadership position.

As regards to age of respondents, women employees with in the age range of 31-40 nine of them were participating in either top or deputy leadership position while the remaining women in different age categories did not occupy leadership position. Age of women employees was found as it had significant association with participation in leadership position in the results of Chi-square with $\mathrm{X}^{2}=20.305, \mathrm{p}<.001$.

\subsection{Inferential Statistics}

Before running multiple linear regressions in the study different assumptions of the model such as multicollinearity, Heteroscedasticity, normality and linearity were checked and the result of the multicollinearity test is here below and the remaining assumption test results are attached on the appendix part.

\section{Multicollinearity Test}

To detect the problem of multicollinearity among the explanatory variables, variables of the study were assessed the multicollinearity test before running model. The most common estimation technique of multicollinearity is a Variance Inflation Factor (VIF) for continuous variable which were included in the empirical models. If Tolerance is above 0.2 and VIF is greater than 10 indicates there is a series multicollinearity problem (Gujarati, 2004). As it is possible to notice from the table below all the value of tolerance for each explanatory variable are above 0.2 and VIF is below 10 . Thus, we can conclude that there is multicollinearity problem.

\begin{tabular}{|c|c|c|c|c|}
\hline \multicolumn{5}{|c|}{ Table 4.2.Multi-collinearity Test } \\
\hline \multirow{2}{*}{\multicolumn{3}{|c|}{ Personal Factors }} & Tolerance & VIF \\
\hline & & & .840 & 1.191 \\
\hline \multicolumn{3}{|c|}{ Organizational factors } & .822 & 1.216 \\
\hline \multicolumn{3}{|c|}{ Socio- cultural factors } & .915 & 1.093 \\
\hline \multicolumn{3}{|l|}{ Age } & .881 & 1.136 \\
\hline \multicolumn{3}{|c|}{ Marital Status } & .799 & 1.252 \\
\hline \multicolumn{5}{|c|}{ Table 4.3.Model Summary } \\
\hline Model & $\mathrm{R}$ & R Square & Adjusted R Square & Std. Error of the Estimate \\
\hline 1 & $.789^{a}$ & .622 & .615 & .81891 \\
\hline \multicolumn{5}{|c|}{ a. Predictors: (Constant), Marital Status, persona factors, socio- cultural factors, Age, organizational factors } \\
\hline \multicolumn{5}{|c|}{ b. Dependent Variable: leadership participation } \\
\hline
\end{tabular}




\begin{tabular}{|c|c|c|c|c|c|c|}
\hline \multirow{2}{*}{\multicolumn{2}{|c|}{ Model }} & \multicolumn{2}{|c|}{ Unstandardized Coefficients } & \multirow{2}{*}{$\begin{array}{c}\text { Standardized Coefficients } \\
\text { Beta }\end{array}$} & \multirow[t]{2}{*}{$\mathrm{T}$} & \multirow[t]{2}{*}{ Sig. } \\
\hline & & $\mathrm{B}$ & Std. Error & & & \\
\hline \multirow[t]{6}{*}{1} & (Constant) & -.441 & .192 & & -2.296 & .022 \\
\hline & Personal factors & .302 & .039 & .320 & 7.825 & $.000 * *$ \\
\hline & Organizational factors & .282 & .040 & .290 & 7.019 & $.000 * *$ \\
\hline & Socio- cultural factors & .259 & .048 & .213 & 5.430 & $.000 * *$ \\
\hline & Age & .051 & .025 & .082 & 2.049 & $.041 *$ \\
\hline & Marital Status & .355 & .043 & .346 & 8.252 & $.000 * *$ \\
\hline
\end{tabular}

a. Dependent Variable: Leadership participation

Note: * and ** are level of significance at 5 and $1 \%$ respectively.

Tables 4.4.reveals that personal factors had statistically significant influence $(\beta=0.320, p<.001)$ on women's low participation of women in leadership positions in the study area. This indicates that $32 \%$ of the causes for women's low participation are personal factors. This result is consistent with the findings of Genet B.(2021) and Singh and Shahabudin, 2000. Similarly, organizational factors had affected $(\beta=0.290, \mathrm{p}<.001)$ the low participation of women leadership positions in the study area. The studies of Woinshet (2015), Genet B.(2021) and Okafor et al. (2011) also found the same results. This implies organizational factors contribute $29 \%$ for the low participation of women in leadership positions in the study area. Furthermore, socio-cultural factors were influencing positively and significantly $(\beta=0.213, \mathrm{P}<.001)$ affected women's participation in leadership positions. This finding is similar with the findings of the studies of Netsanet (2013) and Wubante D.(2018). This shows that socio-cultural factors had $21.3 \%$ contribution for the low participation of women in top leadership positions.

Age had statistically significant effect with $\beta=0.08$ at $p<0.05$. Marital status had also a positive and significant influence with $\beta=0.346$ on women's low participation in leadership positions at $p<.001$. This indicates that the contributions of age and marital status for women's low participation in leadership positions are $8 \%$ and $34.6 \%$ respectively.

Using the results in multiple linear regressions model above, the model of the study is:

Low participation of women in top leadership position $=-0.441+0.302$ (Personal factors) $+0.282($ Organization factors $)+0.259$ (Socio-cultural factors) +0.051 (Age) +0.355 (Marital status) $+\varepsilon$

\section{Conclusions and Recommendations}

Women's engagement in organizations is almost as equal as men but their participation in leadership positions is low. This has become a major problem in Ethiopia. Different researches done on this issue, but there is no agreement which factor contributes most to the problem. This study found marital status, personal factors, organizational factors, socio-cultural factors affected women's low participation in leadership positions in the study area. Thus, the researchers recommend that the concerned body should plan and implement programs such as training programs for improving the personal factors such as self-confidence; the administration ought to prepare special affirmative actions, recognitions for their women employees to enable them occupy leadership positions; besides, the administration had better do some motivations for single women employees in order to make them married since it was found that married women took leadership positions compared to single ones. Besides, the administration should retain its new youth women employees and build their leadership capacity regularly. a lot of work should also be done so as improve the views' of the community towards the equal ability of women in leadership positions.

\section{Recommendations for Future Study}

This study used quantitative research approach, but it was better to incorporate the qualitative methods and strengthen the results of the study. It is also delimited to north Shoa zonal administration only, but it was better to investigate the problem in regional and a country level as well. Thus, the researchers recommend future researchers to conduct a better study by improving these limitations and incorporate other variables.

\section{References}

Birhanu, M. (2013). Challenges and opportunities of educating women's leadership and action In their mission foremancipation and change, Discrepancies between policies and practices;. Adama science and Technolog University.

Chisholm, H. (1911). Abyssinia province and town (11th ed.). The Netherlands the Netherlands: Cambridge University Press.

CSA. (2014). National Statistics Report. Addis Ababa, Ethiopia.

Genet, B. (2020). Factors Affecting Women Participation in Leadership Position: The Case of Debre Markos City 
Administration. Asian ofJournal Humanity, Art and Literature; Volume 7, No 1.

Gojjam, S. a. (2015). Factors Affecting Women's Participation in Leadership and Management in Selected Public Higher Education institutions in Amhara Region, Ethiopia. European Journal of Business and Management.ISSN 2222-1905 (Paper) ISSN 2222-2839 (Online).Vol.7, No.31.

Gujarati. (2004). Basic Econometrics. (4, Ed.) the Mcgraw-Hill.

Nigist, M. (2019). Challenges and Opportunities of Women Empowerment in Leadership Position in Ethiopia. European Journal of Business and ManagementISSN 2222-1905 (Paper) ISSN 2222-2839 (Online) DOI: 10.7176/EJBM.

Ogato, G. (2013). The quest for gender equality and women's empowerment in least developed countries:Policy and strategy implications for achieving millennium development goals in Ethiopia. International. Journal of Sociology and Anthropology. Vol.5, No.9.

Rahel, A. (2013). Opportunities and challenges of women managers in selected organizations, A.A, Ethiopia,. Master's Thesis.

Sila, M. (2015). Household demand for housing in Kenya. University Library of Munich, Germany.

Thornton, B. (2012). Women in senior management: international business report.

Wubante, D. (2018). Women Participation in Managerial Positions in Debreberhan Town, Ethiopia: Challenges and Tactics. International Journal of Science and Research (IJSR) ISSN: 2319-7064.

Annex One: OLS Assumption Test Results

\section{APPENDIX}

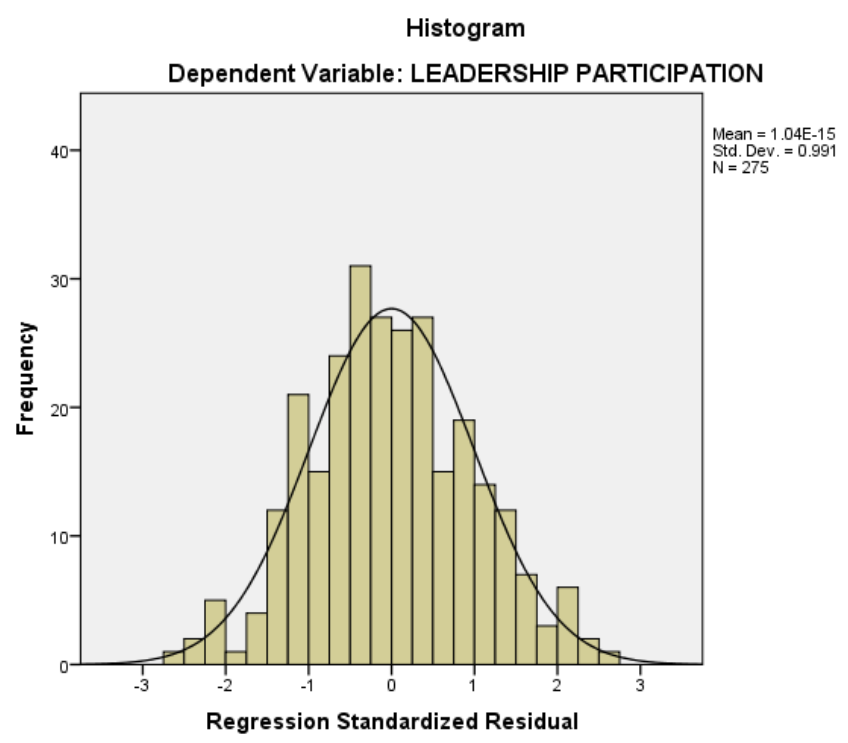

Normality Test

Normal P-P Plot of Regression Standardized Residual

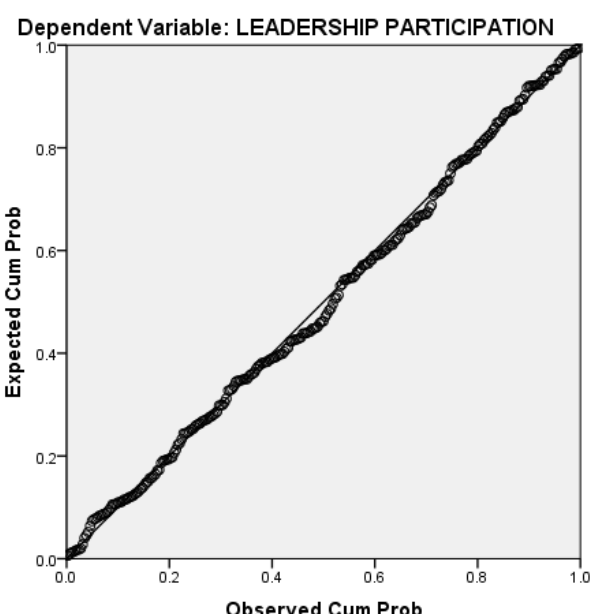

Normality Test 


\section{Annex Two: Correlation Results}

\begin{tabular}{|c|c|c|c|c|c|c|c|}
\hline \multicolumn{8}{|c|}{ Correlations Matrix } \\
\hline & & Age & $\begin{array}{c}\text { Marital } \\
\text { Status }\end{array}$ & $\mathrm{PF}$ & $\mathrm{OF}$ & $\mathrm{SCF}$ & $\begin{array}{l}\text { Women's participation } \\
\text { in leadership }\end{array}$ \\
\hline \multirow[t]{3}{*}{ Age } & $\begin{array}{l}\text { Pearson } \\
\text { Correlation }\end{array}$ & 1 & $.282^{* *}$ & $.220^{* *}$ & $.205^{* *}$ & $.149^{*}$ & $.341^{* *}$ \\
\hline & Sig. (2-tailed) & & $.000 * *$ & $.000 * *$ & $.001 * *$ & $.013 *$ & $.000 * *$ \\
\hline & $\mathrm{N}$ & 275 & 275 & 275 & 275 & 275 & 275 \\
\hline \multirow[t]{3}{*}{ Marital Status } & $\begin{array}{l}\text { Pearson } \\
\text { Correlation }\end{array}$ & $.282^{* *}$ & 1 & $.231^{* *}$ & $.300^{* *}$ & $.267^{* *}$ & $.587^{* *}$ \\
\hline & Sig. (2-tailed) & .000 & & $.000 * *$ & $.000 * *$ & $.000 * *$ & $.000 * *$ \\
\hline & $\mathrm{N}$ & 275 & 275 & 275 & 275 & 275 & 275 \\
\hline \multirow[t]{3}{*}{$\mathrm{PF}$} & $\begin{array}{l}\text { Pearson } \\
\text { Correlation }\end{array}$ & $.220^{* *}$ & .231 & 1 & $.347^{* *}$ & -.013 & $.515^{* *}$ \\
\hline & Sig. (2-tailed) & .000 & $.000 * *$ & & $.000 * *$ & .825 & $.000 * *$ \\
\hline & $\mathrm{N}$ & 275 & 275 & 275 & 275 & 275 & 275 \\
\hline \multirow[t]{3}{*}{$\mathrm{OF}$} & $\begin{array}{l}\text { Pearson } \\
\text { Correlation } \\
\end{array}$ & $.205^{* *}$ & $.300^{* *}$ & $.347^{* *}$ & 1 & .068 & $.536^{* *}$ \\
\hline & Sig. (2-tailed) & .001 & $.000 * *$ & $.000 * *$ & & .258 & $.000 * *$ \\
\hline & $\mathrm{N}$ & 275 & 275 & 275 & 275 & 275 & 275 \\
\hline \multirow[t]{3}{*}{$\mathrm{SCF}$} & $\begin{array}{l}\text { Pearson } \\
\text { Correlation }\end{array}$ & $.149^{*}$ & $.267^{* *}$ & -.013 & .068 & 1 & .333 \\
\hline & Sig. (2-tailed) & .013 & $.000 * *$ & .825 & .258 & & $.000 * *$ \\
\hline & $\mathrm{N}$ & 275 & 275 & 275 & 275 & 275 & 275 \\
\hline \multirow[t]{3}{*}{$\begin{array}{l}\text { Women's participation } \\
\text { in leadership }\end{array}$} & $\begin{array}{l}\text { Pearson } \\
\text { Correlation }\end{array}$ & $.341^{* *}$ & $.587^{* *}$ & $.515^{* *}$ & $.536^{* *}$ & $.333^{* *}$ & 1 \\
\hline & Sig. (2-tailed) & .000 & $.000 * *$ & $.000 * *$ & $.000 * *$ & $.000 * *$ & \\
\hline & $\mathrm{N}$ & 275 & 275 & 275 & 275 & 275 & 275 \\
\hline \multirow{2}{*}{\multicolumn{8}{|c|}{ *. Correlation is significant at the 0.05 level (2-tailed). }} \\
\hline & & & ed). & & & & \\
\hline \multicolumn{8}{|c|}{$\mathrm{PF}=$ Personal factors; $\mathrm{SCF}=$ Socio cultural factors ; $\mathrm{OF}=$ Organizational factors } \\
\hline
\end{tabular}

